\title{
Lumbar Subarachnoid Neurocysticercosis: A Case Report with Literature Review
}

\author{
Kanakam Chandrakanth ${ }^{1} \quad$ Krishna Kumar G. ${ }^{1 \oplus}$ Ravi Suman Reddy ${ }^{1} \quad$ Kartik Manoj Multani $^{1 \oplus}$ \\ ${ }^{1}$ Department of Neurosurgery, Yashoda Hospital, Secundrabad, \\ Telangana, India

\begin{abstract}
Address for correspondence Krishna Kumar G., MCh, Departmen of Neurosurgery, Yashoda Hospital, Alexander Road, Shivaji Nagar, Secundrabad 500003, Telangana, India (e-mail: krishnagova1@gmail.com).
\end{abstract}

Indian J Neurosurg 2022;11:271-273

\begin{abstract}
Keywords

- lumbar IDEM

- spinal neurocysticercosis

- lumbar cyst

Neurocysticercosis (NCC) is the most common parasitic infection of brain. Spinal NCC is commonly seen in association with cranial lesions. However, they do present rarely as isolated spinal lesions. Spinal NCC may present with vague symptoms, pain, paraparesis or, sometimes as, cauda equina syndrome. Spinal NCC with neurological deficits is an emergency, and it should be operated immediately followed by antiparasitic medications. We report a primary lumbar NCC patient, who presented with radicular pain. She underwent complete excision of cyst.
\end{abstract}

\section{Introduction}

Neurocysticercosis (NCC) is the most common parasitic infliction of the central nervous system (CNS), which is caused by pork tapeworm Tenia solium. ${ }^{1}$ The term primary spinal cysticercosis (PSC) indicates isolated involvement of spine and spinal parameningeal structures without coexisting brain inclusion. PSC accounts for 1 to $3 \%$ of overall NCC. ${ }^{2}$ Thoracic spine is the most commonly involved region in PSC, with lumbar and cervical being rarely reported. Clinical presentation for lumbar PSC is highly variable and can present with focal axial back pain or with spectrum of lower limb weakness, ranging from paresis to catastrophic cauda equine syndrome. ${ }^{3}$ In this case report, we share our experience on rare PSC, and one of the few reports where preoperative diagnosis of NCC was suspected based on MRI 3D constructive interference in steady state (CISS) imaging.

\section{Case Report}

A 21-year-old female presented with insidious onset and gradual progressive pain in right gluteal region, radiating to posterior aspect to thigh and leg since 1 month, with difficulty experienced in walking due to pain. Initially, the patient was managed conservatively, after which her pain decreased

DOI https://doi.org/ 10.1055/s-0041-1722833 ISSN 2277-954X. in intensity, and she was able to walk after few days. When she developed radiating pain again, she presented to our outpatient department and we examined her, and there were no motor or sensory deficits. We planned MRI of lumbosacral (LS) spine.

Sagittal and coronal images of MRI LS spine with 3D CISS were suggestive of well-defined thin-walled cystic lesion in spinal canal at L3-L4 level, measuring $38 \times 9 \times 10 \mathrm{~mm}$ with nodular soft-tissue component seen in posteroinferior aspect of cystic lesion, measuring $4 \times 4 \times 3 \mathrm{~mm}$ ( - Fig. 1). Based on imaging findings, a preoperative diagnosis of lumbar intradural extramedullary (IDEM) parasitic cyst (NCC) was made. No evidence of NCC was found in MRI of brain. USG abdomen and X-ray chest were unremarkable.

L3-4 laminectomy was done, with patient under general anesthesia and in prone position. No evidence of extradural lesion. Upon incising dura, gray white flap-like, thin-walled cystic lesion was noted at L3 and L4 vertebral levels, which popped out with pulsations and removed whole as a single piece. In view of NCC, copious irrigation of cavity was done with $3 \%$ saline. Watertight dural closure was done, and the wound was closed in layers.

Gross specimen was cystic in nature, grayish in color, and of size $4 \times 2 \times 2 \mathrm{~cm}$ ( - Fig. 1). Microscopic examination of

\section{(c) 2022. Neurological Surgeons' Society of India.}

This is an open access article published by Thieme under the terms of the Creative Commons Attribution-NonDerivative-NonCommercial-License, permitting copying and reproduction so long as the original work is given appropriate credit. Contents may not be used for commercial purposes, or adapted, remixed, transformed or built upon. (https://creativecommons.org/licenses/by-nc-nd/4.0/).

Thieme Medical and Scientific Publishers Pvt. Ltd. A-12, 2nd Floor Sector 2, Noida-201301 UP, India 

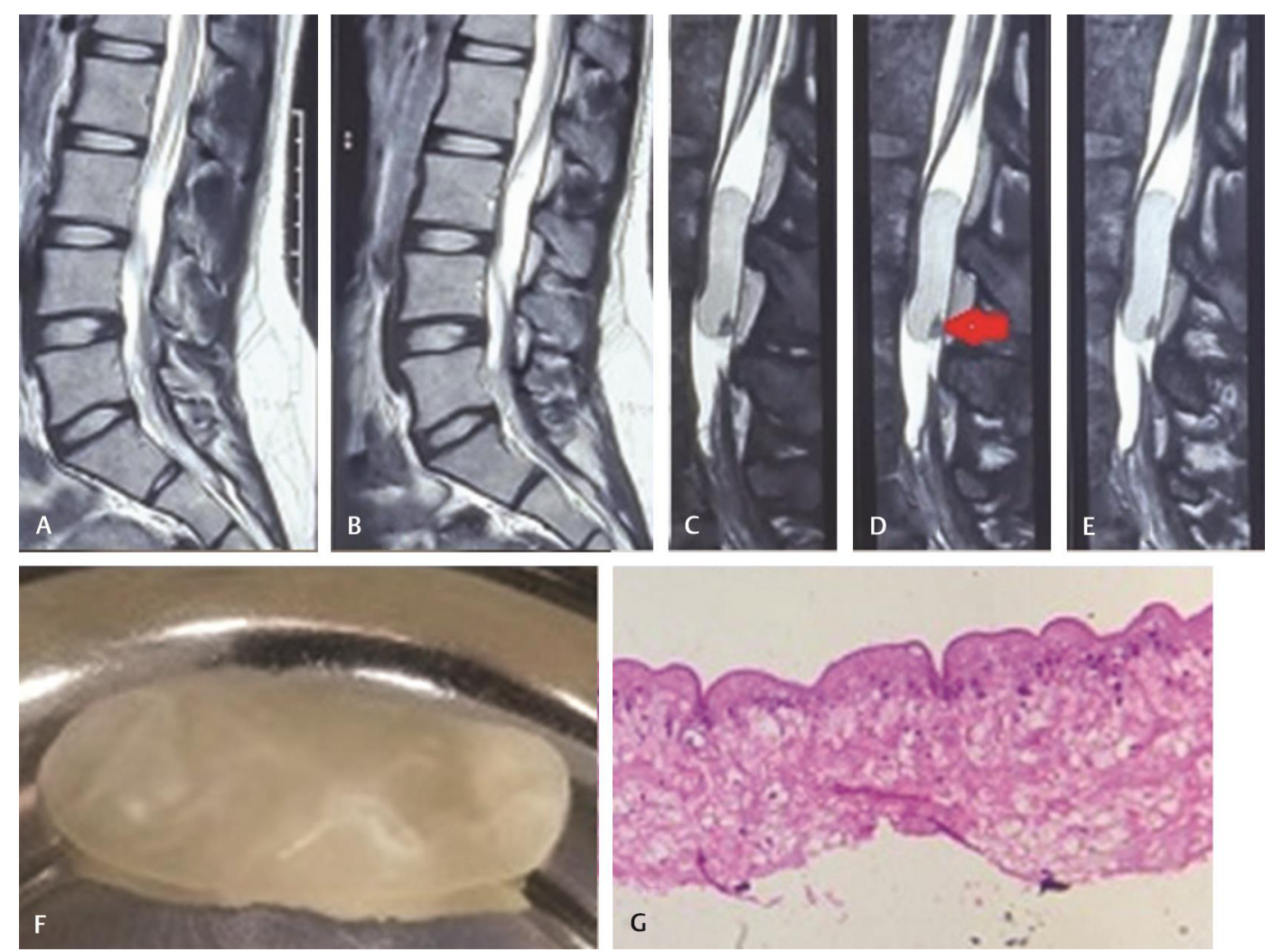

Fig. 1 (A,B) T2 sagittal sections showing hyperintense thin-walled cystic lesion at L3-4 level, located posteriorly within the dura and displacing the cord structures anteriorly. (C-E) T2 constructive interference in steady state (CISS) sagittal images showing a cystic lesion with a small mural nodule posteroinferiorly (red arrow). (F) Gross image of neurocysticercosis (NCC). (G) Histopathology section of cystic wall s/o NCC.

sections showed cyst wall that was undulating, with three distinct layers: outer cuticular, middle cellular, and inner fibrillary layer, which is suggestive of parasitic cyst, favoring cysticercosis (-Fig. 1).

Perioperative and postoperative periods were uneventful. The patient was treated with tablet albendazole for 28 days along with steroids for a week. She was ambulated on postoperative day 2. By postoperative day 4 , she was completely relieved of pain and discharged. The patient was followed-up after 6 weeks of surgery without any complaints/ complications.

\section{Discussion}

PSC is a rare entity which accounts for approximately 1 to $3 \%$ of all recorded NCC cases. ${ }^{4}$ NCC of spine presents either extradural or intradural forms. Intradural is further subclassified into intradural extramedullary/subarachnoid and intramedullary form. Subarachnoid form is more common than intramedullary. Extradural lesion may be only extradural lesion, osseous lesion, or combined. NCC presents with either univesicular or multivesicular form, and the former is more common. Intramedullary NCC occurs through hematogenous spread, whereas the subarachnoid form by direct cerebrospinal fluid (CSF) dissemination. ${ }^{5}$ Previously reported lumbar PSC in literature are mentioned in - Table $\mathbf{1}$.
Neurologic manifestations mainly depend upon number of cysts, location, size, stage of cysticercus larvae, severity of disease activity, and host immune response. Clinical presentation of PSC may be nonspecific and varied, with symptoms ranging from vague pain, parasthesias, and weakness of limbs to cauda equine syndrome. ${ }^{6}$

Main differential diagnosis of IDEM spinal cystic lesion is arachnoid cyst; others include hydatid cyst, dermoid tumors, and spinal subarachnoid cystic tumors. ${ }^{7}$ To differentiate it from the arachnoid cyst, PSC cyst wall is enhanced in postgadolinium T1 contrast images. The 3D-CISS/fast imaging employing steady-state acquisition (FIESTA) sequence of MR imaging well demarcates cyst from surrounding. Cysts with mural nodule are better visualized in 3D-CISS sequence, which confirms the preoperative diagnosis of spinal NCC. ${ }^{8,9}$

Management of spinal NCC includes both surgical and medical. Urgent surgical decompression should be performed when patient presents with neurological deficits/ pain. Care should be taken not to puncture the cyst wall and contaminate the surgical field. Spillage of contents leads to recurrence. Once removed, then copious irrigation of operative area should be performed with either $3 \%$ saline or diluted povidone-iodine solution, which acts as larvicidal agent. Medical management includes albendazole, praziquantel, and steroids. Albendazole has better CNS penetration. Steroids are given to reduce inflammatory reactions. 
Table 1 Literature on primary lumbar neurocysticercosis

\begin{tabular}{|c|c|c|c|c|}
\hline Author & Age/sex & Symptom/sign & Preoperative diagnosis & Lesion level \\
\hline Paterakis et al ${ }^{1}$ & $60 / M$ & Left foot drop & Hydatid cyst & L5-S1 \\
\hline Jang et $\mathrm{al}^{2}$ & $50 / \mathrm{M}$ & $\mathrm{B} / \mathrm{L}$ leg pain & Cysticercosis & L4-S1 \\
\hline Jongwuties et al ${ }^{7}$ & $59 / F$ & Urinary retention & Arachnoid cyst & L1-L4 \\
\hline Park et $\mathrm{al}^{9}$ & $72 / \mathrm{M}$ & Left leg pain & Tumor/Tuberculoma & L4-S1 \\
\hline Yoo et al ${ }^{11}$ & $42 / \mathrm{M}$ & Back pain & Arachnoid cyst & $\mathrm{T} 11-\mathrm{S} 1$ \\
\hline Ganesan et $a^{3}$ & $32 / \mathrm{M}$ & Cauda equina & Subarachnoid cyst/ Hydatid cyst & L2-S1 \\
\hline Zhang et al & $59 / \mathrm{F}$ & B/L LL pain & Not described & $\mathrm{L} 1 / 2-\mathrm{S} 1$ \\
\hline Han et $\mathrm{al}^{12}$ & $59 / \mathrm{M}$ & Left leg pain & Not described & L1-L5 \\
\hline Bansal et al ${ }^{13}$ & $40 / \mathrm{M}$ & Low back ache & Tarvlov cyst & L5-S1 \\
\hline Sharma et al ${ }^{14}$ & $48 / \mathrm{F}$ & Low back ache & Adhesive arachnoiditis/epidermoid & L2-S2 \\
\hline
\end{tabular}

Steroids increase the levels of albendazole when coadministered, but levels of praziquantel are diminished. ${ }^{10}$

\section{Conclusion}

In an endemic country like India, any spinal intradural mass lesion NCC should undergo differential diagnosis, and to confirm it preoperatively, we suggest 3D-CISS sequence of MR imaging along with $\mathrm{T} 1$ postgadolinium contrast images as a diagnostic tool.

\section{Conflict of Interest}

None declared.

\section{References}

1 Paterakis KN, Kapsalaki E, Hadjigeorgiou GM, Barbanis S, Fezoulidis I, Kourtopoulos H. Primary spinal intradural extramedullary cysticercosis. Surg Neurol 2007;68(3):309-311

2 Jang J-W, Lee J-K, Lee J-H, Seo B-R, Kim SH. Recurrent primary spinal subarachnoid neurocysticercosis. Spine 2010;35(5):E172-E175

3 Ganesan S, Acharya S, Kalra KL, Chahal R. Intradural Neurocysticercosis of Lumbar Spine: A Case Report. Global Spine J 2015;5(4):e1-e4

4 Colli BO, Assirati Júnior JA, Machado HR, dos Santos F, Takayanagui OM. Cysticercosis of the central nervous system. II. Spinal cysticercosis. Arq Neuropsiquiatr 1994;52(2):187-199
5 Prasad KN, Prasad A, Verma A, Singh AK. Human cysticercosis and Indian scenario: a review. J Biosci 2008;33(4):571-582

6 Leite CC, Jinkins JR, Escobar BE, et al. MR imaging of intramedullary and intradural-extramedullary spinal cysticercosis. Am J Roentgenol 1997;169(6):1713-1717

7 Jongwutiwes U, Yanagida T, Ito A, Kline SE. Isolated intradural-extramedullary spinal cysticercosis: a case report. J Travel Med 2011;18(4):284-287

8 do Amaral LL, Nunes RH, da Rocha AJ. Parasitic and rare spinal infections. Neuroimaging Clin N Am 2015;25(2):259-279

9 Park Y-S, Lee JK, Kim J-H, Park K-C. Cysticercosis of lumbar spine, mimicking spinal subarachnoid tumor. Spine J 2011;11(4):e1-e5

10 Corral I, Quereda C, Moreno A, et al. Intramedullary cysticercosis cured with drug treatment. A case report. Spine 1996;21(19):2284-2287

11 Yoo M, Lee CH, Kim KJ, Kim HJ. A case of intradural-extramedullary form of primary spinal cysticercosis misdiagnosed as an arachnoid cyst. Journal of Korean Neurosurgical Society 2014;55(4):226.

12 Han SB, Kwon HJ, Choi SW, Koh HS, Kim SH, Song SH, Youm JY. Lumbar intradural neurocysticercosis: A case report. Korean Journal of Spine. 2014;11(3):205

13 Bansal R, Gupta M, Bharat V, Sood N, Agarwal M. Racemose variant of neurocysticercosis: a case report. Journal of Parasitic Diseases. 2016;40(2):546-549

14 Sharma BS, Garg A. Isolated spinal neurocysticercosis with clinical pleomorphism. Turkish Neurosurgery. 2008;18(3):294-297 